\title{
Comparative Analysis of Modal Auxiliary Verbs in English and in Chinese
}

\author{
ZHANG Hong-yan \\ Jinan University, Guangzhou, China
}

\begin{abstract}
The study of modal auxiliary verbs has been done by comparing modal auxiliary verbs in English with the ones in Chinese qualitatively and quantitatively. The modals in English and in Chinese are statistically analyzed through their forms and meanings. The data consists of 50 pieces of Chinese prose with their 50 English translation versions called corpus A and 50 pieces of English prose with their Chinese translation versions called corpus B, altogether 200 articles, which represent a type of discourse that is rich in modal auxiliary verbs both in English and in Chinese. The major findings are as follows: (1) The three criteria: inversion, negation, and the use of pro-forms can be used to define both English and Chinese auxiliaries; (2) the modals of both languages can be analyzed within the same semantic categories: volition, probability, and necessity; (3) Chinese epistemic modals can have inversion patterns; (4) the negative forms of Chinese modals are more complex than those of English modals; and (5) the statistic analysis shows that the modals in probability category both in English and in Chinese are used much more often compared to the other two categories: volition and necessity and that deontic modals are used much fewer in both languages to express necessity.
\end{abstract}

Keywords: modal auxiliary verb, volition, probability, necessity, epistemic, deontic

\section{Introduction}

Modal auxiliary verbs indicate attitudes of the speaker/writer towards the state or event expressed by another verb, i.e., indicate different types of modality. The study of modal auxiliary verbs has long been a major focus of interest for both Western and Chinese scholars. They all consider the modal auxiliaries as an important form of expression for modality. What makes the modal auxiliary verb so difficult to account for is that its meaning has both a logical and a practical (or pragmatic) element. Although there is still no unified definition, the nature of modality which is often expressed by modal auxiliary verbs has traditionally been discussed in terms of such notions as volition, probability, and necessity (Jespersen, 1924; Lyons, 1977; Palmer, 1979, 1986/2001). In philosophical semantics, probability is referred as "epistemic" modality, obligation or necessity as "deontic" modality and volition as "dynamic" modality. Of those studies which are attempted to relate to a systematic explanation of modality, such linguists as Bolinger (1977), Coates (1983), Hatav (1997), Huddleson (1988), Perkins (1980, 1983), Quirk (1985), and White (1975) provide the fullest account and represent the major achievement in the study of English modals.

ZHANG Hong-yan, associate professor, master, College of Foreign Studies, Jinan University. 
All those researches and studies enable the reader to have deep understanding of what modal auxiliary verbs are like in English.

Chinese modal auxiliary verbs were first noticed by MA Jian-zhong (1845-1900), the first scholar who made an analysis of Chinese grammar by means of the approach applied by Western grammarians. In MA's grammar, he named “可 ke”, “能 neng”, “得 dei”, etc. as auxiliary words which are followed by verbs. From then on, many Chinese scholars have made elaborate studies on auxiliary verbs or volitive auxiliaries in Chinese and in English (DING, 1979; J. A. LI, 1999; C. H. LI, 2008; K. X. LI, 2007; GAO, 1986; Y. S. HU \& FAN, 1995; LIU, 1960; LU \& D. X. ZHU, 1953; WANG, 1985; F. L. ZHAO, 2009; Y. R. ZHAO, 1979; P. ZHAO, 2004; G. M. ZHU, 2005). As for these studies, one of the problems is how to distinguish the auxiliary verbs in Chinese. LIU Jian (1960) insisted that auxiliary verbs or volitive auxiliaries be different from verbs and that they should be regarded as a sub-category of the verb. Another problem is how to analyze the modals-whether from the point of form or from that of meaning.

The purpose of this study is to make a comparative analysis of the modal auxiliaries in both English and Chinese by combining the form with the meaning. In this way, a better understanding of the similarities and the differences between them can be achieved.

\section{The Forms and Meanings of Modal Auxiliary Verbs}

Since modal auxiliary verbs indicate different types of modality, the study can talk about them in terms of such notions as "permission" and "necessity", and the study also has to consider ways in which these notions become remolded by the psychological pressures—such factors as consideration, politeness, tact, and irony.

\section{English Modal Auxiliary Verbs}

In English, auxiliary verbs are, as the name implies, “helping verbs”. They have no independent existence as verb phrases, but only help to make up verb phrases. Quirk (1972, p. 82) classified auxiliary verbs into primary auxiliary verbs and modal auxiliary verbs. The latter contributes modality expressing such concept as volition, probability, and insistence. The author lists the modal auxiliary verbs according to the three semantic categories in Table 1.

Table 1

The Semantic Categories of English Modal Auxiliary Verbs

\begin{tabular}{|l|l|}
\hline English modal auxiliary verbs & Semantic category \\
\hline will, would, shall, should, would rather, would like, dare & Volition (7) \\
\hline can, could, may, might, must, will, would, shall, should, used to & Probability (10) \\
\hline need,ought to, shall, should, must & Necessity (5) \\
\hline
\end{tabular}

It is well known that the three criteria to define English auxiliaries are inversion, negation, and the use of pro-forms. English modal auxiliary verbs do share the three characteristics with primary auxiliaries DO, HAVE, and BE.

Inversion. English modals can appear before the subject in the following cases:

(1) In an interrogative sentence:

Example (1) (English original) “Can it be that I have a secret admirer?” she would ask.

(Paul Villard: A Bouquet for Miss Benson) 


\section{(Chinese translation) 她会问：“是不是有人喜欢我，又不肯说？”}

(ta hui wen: "shibushi youren xihuan wo, you buken shuo?”)

Example (2) (English original) How could he let them down? (Lynn Rosellin: Doug Heir)

(Chinese translation) 他怎么能让他们失望呢 ? (ta zenme neng rang tamenshiwangne?)

(2) When a conjunction as is used:

Example (3) (English original) This eagle can see between four and eight times as much detail as can humans. (Bruce Gooding: Killer on Wings Is Under Threat)

(Chinese translation) 大雕看清细节的能力比人类要强四至八倍。

(dadiao kanqing xijie de nengli bi renlei yao qiang si zhi ba bei.)

Negation. English modals can be followed by "not" to form contracted negative forms:

Example (4) (English original) That night I couldn’t sleep.

(Ralph Moody: A Boy and His Father Became Partners)

(Chinese translation) 那天晚上我怎么也睡不着。

(natian wanshang wo zenme ye shuibuzhao.)

However, not all the modals have the contracted negative forms. For example, “mayn't” is restricted to BrE, "shan't" is rare in AmE.

The use of pro-forms. English modals can be used to substitute for the whole verb phrases to avoid repetition.

Example (5) (English original) “They want me to let go,” he said, “but I can’t. I don’t want to.”

(Joanne J. Henry: Promise of Bluebirds)

(Chinese translation) 他说，“他们想要我松手，可是我不能松，我不想松。”

(ta shuo, "tamen xiang yao wo songshou, keshi wo buneng song, wo buxiang song.)

\section{Chinese Modal Auxiliary Verbs}

Up till now, few Chinese grammarians have defined exactly Chinese modal auxiliary verbs. Some adopt the approach to giving a demonstration to show the properties of modals, others define the modal auxiliary verbs from the point of meaning. For example, in Modern Chinese edited by HU Yu-shu (1981, p. 319), auxiliary verbs are called the verbs that express probability. ZHU De-xi involves auxiliary verbs into real predicate object verbs whose object can be verbs, or adjectives, or subject-predicate construction, predicate-object construction, predicate-complement construction, and group with consecutive predicates, or the groups consisting of an adverb modifier and the word it modifies. Obviously, ZHU De-xi (1982, p. 61) defines auxiliary verbs from form.

HUANG Bo-rong and LIAO Xu-dong (1983, p. 317) combine the form with meaning and define the Chinese auxiliary verbs as the verbs that can be used in front of lexical verbs or adjectives to express willingness, probabilities, and necessities. LI Ling-ding defines auxiliary verbs in Modern Chinese Verbs (1990, p. 140) as follows: Auxiliary verbs are verbs that express volition, probability, and necessity. In a syntactic structure auxiliary verbs often appear between subject and another verb phrase to act on the helping function of the predicate. Table 2 generalizes Chinese auxiliary verbs. 
Table 2

The Semantic Categories of Chinese Modal Auxiliary Verbs

\begin{tabular}{|l|l|}
\hline Chinese modal auxiliary verbs & Semantic category \\
\hline 爱 ai (like, love), 打算 dasuan (intend), 敢 gan (dare), 乐意 leyi (would like), 肯 ken (be \\
willing to), 情愿庁愿 qingyuan/ningyuan (would rather), 想 xiang (would like), 要 yao (will, \\
would), 愿(意) yuan(yi) (be willing to), 准备 zhunbei (prepare)
\end{tabular}

Similar to English modals, Chinese modals also have a close set and can be analyzed within such semantic categories as volition, probability, and necessity. This study makes use of the three criteria of auxiliary verbs to analyze Chinese modal auxiliary verbs.

Inversion. An epistemic modal, according to Halliday (1970, p. 327), expresses the speaker's assessment of the probability of what he is saying. In this case, the modal has the whole clause as its argument. Therefore, the modal can be put before the subject to make an inversion sentence.

Example (6) (Chinese original) 我可能是从天津来的。(wo keneng shi cong Tianjin lai de.)

(Hou Baolin: I Might Have Come from Tianjin)

(English translation) I might have come from Tianjin.

Inversion: 可能我是从天津来的。(keneng woshi cong Tianjin lai de.)

However, 会 (hui) “future-predicate” cannot be used in this way (see Example (7)). The reason is that 会 (hui) is not yet a full-fledged epistemic modal.

Example (7) (Chinese original) 他会愉快地退下来。(ta hui yukuaide tui xialai.)

(Yi Yun: Sportsmen's Values)

(English translation) He will step down happily.

$\times$ 会他愉快地退下来。(hui ta yukuaide tui xialai.)

Negation. In Chinese, the negative forms of modal auxiliary verbs are very complex.

(1) Most Chinese modals have direct negative forms. Some modals can use either 不 (bu) or 没床 (mei/wei):

Example (8) (Chinese original) 谁都不能避免失败。(shui dou buneng bimian shibai.)

(Feng Jicai: A Bouquet of Flowers for You)

(English translation) Nobody can avoid failure.

(2) Indirect negative forms, such as 不一定 (buyiding), 未必不见得 (weibi/bujiande):

Example (9) (Chinese original) 他不一定肯来。(ta buyiding ken lai.)

(English translation) It is likely that he is unwilling to come.

(3) Multiple negative forms:

Example (10) (Chinese original) 他现在做父亲的心 , 不得不无限地痛苦。

(ta xianzai zuo fuqin de xin, budebu wuxiande tongku.) 
(Feng Xuefeng: The Old Man and His Three Sons)

(English translation) Being a father, he was now suffering from a broken heart.

The use of pro-forms. Similar to English modals which can be used to substitute for the whole verb phrases, in a specific language circumstance, Chinese modals can also be used to act on the core of the predicate.

Example (11) (Chinese original) 爹爹说 , “ 你们爱吃花生吗 ?”

(diedie shuo, “nimen ai chi huasheng ma?”)

我们都争着答应 : “爱!” (women dou zhengzhe daying: “ai!”)

(English translation) "Do you like peanuts?” Dad asked.

"Yes!” we all answered eagerly.

\section{Brief Review}

From the comparison, the study finds that Chinese auxiliary verbs or volitive verbs and English modal auxiliary verbs do share some common characteristics although they are completely different languages.

The similarities. (1) Both have a close (not open) set of modal auxiliary verbs that can be formally defined (see Table 1 and Table 2).

(2) Both express such concepts as volition, probability, and necessity.

(3) English modal auxiliaries do not have "-s" form for the third person singular. Chinese as a language with few morphological inflections will never change its verb form.

(4) Both are polysemous.

The differences. (1) English modals can be used to substitute for the whole verb phrases to avoid repetition. But in this situation, the subject before the modal cannot be omitted.

Example (12) (English original) “They want me to let go,” he said, “but I can’t. I don’t want to.”

(Joanne J. Henry: Promise of Bluebirds)

(Chinese translation) 他说, “他们想要我松手, 可是我不能松, 我不想松。”

(ta shuo, "tamen xiang yao wo songshou, keshi wo buneng song, wo buxiang song.)

(2) Chinese modal auxiliaries verbs can be followed by predicative adjectives, whereas English modal auxiliary verbs cannot:

Example (13) 我爱热闹，也爱冷静。(wo ai renao, ye ai lengjing.)

I like the noisy situation, and I like the quiet situation, too.

(ZHU Zi-qing: Moonlight over the Lotus Pond)

The reason is that in Chinese adjectives can be used as predicate directly, while in English, auxiliary verb BE or a link verb should be used to form predicate with the adjective.

(3) In the interrogative construction:

English: Modal auxiliary verb+ Subject + Lexical verb?

Example (14) Will that happen to me?

Chinese: a. Subject + Modal auxiliary verb + Lexical verb/Adjective + 吗 (ma)?

b. Subject + Positive modal auxiliary verb + Lexical verb + Negative modal auxiliary verb + Lexical verb?

c. Subject + Positive modal auxiliary verb + Negative modal auxiliary verb + Lexical verb? 
Example (15) (Chinese) 你能去吗? (ni neng qu ma?)

你能去不能去? (ni neng qu bu neng qu?)

你能不能去? (ni neng bu neng qu?)

(English) Can you go (or not?)

While answering the questions, in Chinese, subject can be omitted from the pattern with a modal auxiliary verb, but in English, subject cannot be omitted.

Example (16) (Chinese) 一你能回答这个问题吗 ? (ni neng huida zhege wenti ma?)

一能。(neng.)

(English) - Can you answer this question?

-Yes, I can.

(4) In negative construction, the positions of the negative words are different:

English: Modal auxiliary verb + Not +Lexical verb

Chinese: Not (bu) + Modal auxiliary verb + Lexical verb

Example (17) (English original) That night I couldn't sleep.

(Ralph Moody: A Boy and His Father Became Partners)

(Chinese translation) 那天晚上我怎么也睡不着。

(natian wanshang wo zenme ye shuibuzhao.)

Note here, in Chinese, modal auxiliary verbs can also be followed by negative verb.

Example (18) 我可以不去。(wo keyi bu qu.) I don’t have to go.

But a different meaning will appear in Example (19).

Example (19) 我不可以去。(wo bu keyi qu.) I mustn’t go.

(5) Chinese modal auxiliary verbs can co-occur without any conjunction, but English modal auxiliary verbs cannot.

Example (20) (Chinese original) 我深信我要想买得起昂贵的物品, 首先必须在学业上求上进, 求学历 尽量高些。

(wo shenxin wo yao xiang mai de qi anggui de wuping, shouxian bixu zai xueye shang qiu shangjin, qiu xueli jinliang gao xie.)

(Zaimei: A Shy Dreamer)

(English translation) I was convinced that before I could afford anything expensive, I should climb the academic ladder as high as possible.

\section{Statistical Analysis}

The data consists of 50 pieces of Chinese prose with their 50 English translation versions called corpus A and 50 pieces of English prose with their Chinese translation versions called corpus B, altogether 200 articles, which represent a type of discourse that is rich in modal auxiliary verbs both in English and in Chinese.

\section{The Proportions of the Occurrences of the Modals}

The modals in corpus A are 9.2\% in Chinese and 12.5\% in English; in corpus B, 11\%o in Chinese and 12\%o in English. It is very interesting to note that the proportion of the occurrences of modals in corpus B of Chinese and English are very close (the difference is only 1), although the percentage of the occurrences of modals in 
English is higher. The conlusion is made as follows:

(1) The frequency of the occurrences of modal auxiliary verbs in English is higher than those in Chinese. In corpus A, the frequency of the occurrences in English is $3.3 \%$ and in corpus B, it is higher than $1 \%$.

(2) When translating English pieces of prose into Chinese, the translators tend to be loyal to the modality expressions used by the English authors. Therefore, they try to find the Chinese modals corresponding to the English modals.

\section{Semantic Category}

As mentioned previously, the study analyzes modals in such semantic categories as volition, probability, and necessity. Table 3 shows the percentage of the occurrences of the modals both in English and in Chinese.

Table 3

The Proportions of the Occurrences of the Modals

\begin{tabular}{lllllll}
\hline Category & \multicolumn{2}{c}{ Volition } & \multicolumn{2}{c}{ Probability } & \multicolumn{2}{c}{ Necessity } \\
\hline Language & Chinese & English & Chinese & English & Chinese & English \\
\hline Corpus A & $32.1 \%$ & $26 \%$ & $48.8 \%$ & $55 \%$ & $19.1 \%$ & $19 \%$ \\
Corpus B & $27 \%$ & $29.5 \%$ & $56 \%$ & $55.2 \%$ & $17 \%$ & $15.3 \%$ \\
\hline
\end{tabular}

What should be noted first is that modals expressing probability occur much more frequently both in English and in Chinese. The former's percentage of the occurrences is $55 \%$ and that of the latter is $48.8 \%$ in corpus $\mathrm{A}$; in corpus B Chinese translation versions give some similarity to this phenomenon (56\%). In English, no matter whether in original or in translation versions, modals expressing probability show the similar frequencies of the occurrences (55\%, 55.2\%). Therefore, in both languages, modals expressing probability are commonly used.

Next, in corpus A and corpus B, Chinese volitive modals relatively occur more often than English volitive modals. The percentage of the occurrences is respectively $32.1 \%$ and $29.5 \%$. There are some evidence that Chinese writers prefer to express volition by means of volitive auxiliaries (32.1\%), but when translated into English, the translators use fewer volitive modals, the percentage of the occurrences of the volitive modals is only $26 \%$, the difference is 6.1. The reason is that such Chinese modals expressing volition, i.e., dynamic modality, as 愿意 yuanyi, 乐意 leyi, 爱 $a i$, 肯 ken, 要 yao, 想 xiang, 打算 dasuan, 准备 zhunbei can be expressed by lexical verbs in English, such as be willing to, like, want, desire, intend, or be going to, etc.. On the other hand, Chinese translators use slightly fewer volitive auxiliaries to express English dynamic modality, for the percentage of occurrences of Chinese volitive modals is $27 \%$ in corpus B. However, English modals expressing volition occur more frequently than those of Chinese, the percentage of the occurrences is $29.5 \%$, the difference is 2.5 . This phenomenon shows that some modals expressing volition in English can be expressed in Chinese by certain tone or mood.

Example (21) (English original) A fine blanket—I'll say it is! (Floyd Dell: The Blanket) (Chinese translation) 好毯子一可不是吗! (hao tanzi一kebushi ma!)

Thirdly, compared with the other two semantic categories of volition and probability, deontic modals are used fewer in both languages to express necessity. But English deontic modals show even lower percentage (19\% in corpus A and $15.3 \%$ in corpus B) than Chinese deontic modals (19.1\% in corpus A and $17 \%$ in corpus B). The reason is partly that Chinese modals can be used to express imperative forms while English modals cannot, that 
many other words or patterns can be used to express deontic modality.

\section{Conclusion}

Modal auxiliary verbs are "helping verbs" that contribute to expressing different modality. The modals both in English and in Chinese can be analyzed within such semantic categories as volition, probability, and necessity.

The major findings in similarities are that there exists a close set of modals in both languages, with three semantic categories and that the inversion, negation, and the use of pro-forms can be used to analyze both modals. However, those findings in differences are much more. For example, Chinese epistemic modals have inversion pattern but many other modals do not. The negative forms of Chinese modals are more complex than those of English modals. Statistic analysis shows in the proportions of the occurrences of modals in both languages that modals expressing probability in both languages are used much more compared to those expression volition and necessity and that deontic modals are used much fewer in both languages to express necessity compared to epidemic modals.

This analysis shows an instructive implication to translation from English into Chinese or from Chinese into English.

There exist some problems:

(1) A single modal has several meanings in both English and Chinese and the modal's meaning has both a logical and a practical (or pragmatic) element.

(2) Deontic modality is the modality difficult to account for. Prior research modality has focused primarily on epistemic modality while deontic modality has received relatively less attention. The reason that they are used much less compared to the other two categories: volition and probability is beyond the discussion in this study.

\section{References}

Bolinger, D. (1977). Meaning and form. New York: Longman.

Coates, J. (1983). The semantics of the modal auxiliaries. London \& Canberra: Croom Helm.

DING, S. S. (1979). The lecture of modern Chinese. Beijing: Business Press.

GAO, M. K. (1986). On Chinese grammar. Beijing: Business Press.

Halliday, M. A. K. (1970). Language structure and language function. London: Arnold.

Halliday, M. A. K. (1994). An introduction to functional grammar (2nd ed.). London: Arnold.

Hatav, G. (1997). The semantics of aspect and modality (p. 117). Philadelphia: John Benjamins.

HU, Y. S. (1981). Modern grammar. Shanghai: Shanghai Foreign Language Education Press.

HU, Y. S., \& FAN, X. (Eds.). (1995). Research on Chinese verbs. Zhengzhou: Henan University Press.

HU, Z. L. (1999). Systematic functional grammar and the research on Chinese grammar. In S. X. LU (Ed.), Elementary research on grammar (pp. 252-270). Beijing: Business Press.

HUANG, B. R., \& LIAO, X. D. (Eds.). (1983). Modern Chinese. Lanzhou: Gansu People’s Press.

Huddleson, R. D. (1976). Some theoretical issues in the description of the English verbs. Lingua, (40), 331-333.

Huddleson, R. D. (1988). English grammar: An outline. Cambridge: Cambridge University Press.

Jespersen, O. (1924). The philosophy of grammar. London: Allen \& Unwin.

LI, C. H. (2008). Cognitive building of English modality. Journal of Tianjin Foreign Studies University, (1), 1-7.

LI, J. A. (1999). Modality and the meanings of modal auxiliaries. Journal of Foreign Languages, (4), 19-23.

LI, K. X. (2007). Functions of modal verbs in legal documents and their translation. Chinese Translators Journal, (6), 54-49.

LI, L. D. (1990). Modern Chinese verbs (p. 140). Beijing: China Social Scientific Press.

LIU, J. (1960). On Auxiliary verbs. Chinese of China, (1), 1.

LU, S. X., \& ZHU, D. X. (1953). Lecture of grammar and rhetoric. Beijing: China Youth Press. 
Lyons, J. (1977). Semantics (Vol. 2, pp. 787, 793, 823). Cambridge: Cambridge University Press. MA, J. Z. (1983). Ma’s grammar. Beijing: Business Press.

Palmer, F. R. (1979). Modality and English modals. London: Longman.

Palmer, F. R. (1986/2001). Mood and modality (pp. 18, 21, 33, 102). Cambridge: Cambridge University Press.

Perkins, M. R. (1980). The core meanings of English modals. Linguistics, (18), 245-73.

Quirk, R. (1972/1985). A grammar of contemporary English (pp. 82, 87, 97). London: Longman.

WANG, L. (1985). Chinese modern grammar. Beijing: Business Press.

White, A. R. (1975). Modal thinking. New York: Cornell University Press.

ZHAO, F. L. (2009). An Empirical study on the learning difficulty order of English root and epistemic modals. CELEA Journal, (2), 75-91.

ZHAO, P. (2004). The semantic and pragmatic analysis of English modal auxiliary verbs. Foreign language Research, (2), 11-15.

ZHAO, Y. R. (1979). Chinese speaking grammar. Beijing: Business Press.

ZHU, D. X. (1982). Grammar lecture notes. Beijing: Business Press.

ZHU, G. M. (2005). Modality and Chinese modal verbs. Shandong Foreign Language Teaching, (2), 18-21. 